\title{
Analysis of BTEX in Experimental Columns Containing Neat Gasoline and Gasoline-Ethanol
}

\author{
Irajá N. Filho,* Nathália C. Vieceli, Eduardo M. Cardoso and Eduardo R. Lovatel \\ Center of Exact Sciences and Technology, Institute of Environmental Sanitation, \\ University of Caxias do Sul, Rua Francisco Getúlio Vargas, 1130, Bairro Petrópolis, \\ 95070-560 Caxias do Sul-RS, Brazil
}

\begin{abstract}
O principal objetivo deste trabalho foi o estudo do perfil de evaporação de BTEX (benzeno, tolueno, etilbenzeno e xilenos) em amostras de gasolina pura e mistura de gasolina-etanol. Os vapores de duas colunas lacradas contendo areia de fundo de rio e água destilada foram monitorados por 18 dias por SPME (micro extração em fase sólida). BTEX que permaneceram na fase aquosa e na areia foram extraídos por SPE (extração em fase sólida) e Soxhlet, respectivamente. A análise instrumental foi realizada por cromatografia a gás com detector por ionização de chama (GC/FID). Tolueno e etilbenzeno apresentaram as maiores volatilizações na coluna contendo a mistura gasolina-etanol. Esta distribuição pode ser devida à ocorrência de forças atrativas envolvendo moléculas de etanol e de BTEX. O benzeno foi o composto com maior retenção na fase areia da coluna contendo a mistura gasolina-etanol.
\end{abstract}

The main objective of the present study was to assess the evaporation profile of BTEX (benzene, toluene, ethylbenzene and xylenes) in neat gasoline and gasoline-ethanol blend fuels. The vapors from two sealed columns containing river sand and distilled water were monitored during 18 days by SPME (solid-phase microextraction). BTEX that remained in the water and sand phases were extracted by SPE (solid-phase extraction) and Soxhlet, respectively. Instrumental analysis was performed by gas chromatography using a flame ionization detector (GC/FID). Toluene and ethylbenzene showed the highest volatilizations in the gasoline-ethanol column and the occurrence of attractive intermolecular forces among ethanol and BTEX molecules can be responsible for this distribution. Benzene showed the lowest reduction of concentration in the sand compartment in the gasoline-ethanol column.

Keywords: gasoline, ethanol, BTEX, gas chromatography, volatilization

\section{Introduction}

After the first oil crisis in the 1970s, with the increasing pollution levels and the need for clean energy production, several nations around the world developed programs to support the use of alternative fuels, including ethanol and gasohol (a gasoline-ethanol blend), as automobile fuels. The main advantages of the ethanol-blend fuels are the reduction of greenhouse gas emissions and the higher octane number of gasoline. The ethanol content in Brazilian gasoline ranges from 24 to $25 \%{ }^{1}$

Brazil counts on two national programs aimed at introducing ethanol to its energy matrix. In one program, $20-25 \%$ combustible anhydrous ethyl alcohol (AEAC) is

*e-mail: inascimf@ucs.br blended with gasoline. The volume of the mixture was established by a governmental law, and is dependent upon market and economic variables. ${ }^{1}$ In the other program, combustible hydrated ethyl alcohol (AEHC) is sold as fuel for cars running exclusively on flexible-fuel or alcohol. Anhydrous ethyl alcohol has been used in Brazil since 1939 as a gasoline additive, with percentages varying from 5 to $25 \%$. In 2010/2011 the Brazilian production reached 8 billion and 19.6 billion liters of AEAC and AEHC, respectively (an increase of $7 \%$ in relation to 2009/2010). ${ }^{2}$ The technology used in AEAC makes this product very competitive in both domestic and international markets.

Despite the benefits provided by the mixture, the presence of ethanol in gasoline may affect the BTEX (benzene, toluene, ethylbenzene and xylenes) volatilization process, and these compounds may evaporate from spills 
of underground storage tanks or by accidental releases. Past studies have shown that gas transport through the vadose zone can be influenced by moisture content due to variations in gaseous permeability, phase partitioning and aerobic biodegradation. ${ }^{3}$ In the soil-spill situation, the rate of evaporation is a function of temperature, wind speed, atmospheric conditions, solar radiation, volatility and diffusion characteristics of the fuel and thickness of the vadose zone. $^{4}$

Compounds containing four to six carbon atoms volatilize faster than heavier hydrocarbons. In the case of gasoline, BTEX are the chemicals of greatest concern because of their toxicity and carcinogenic activity. ${ }^{5,6}$ In gasohol, the presence of ethanol can modify the dissolution capacity of BTEX and increase groundwater pollution. Some of these changes reported in the literature are variations of free-phase measurements in monitoring wells, cosolvent effects that increase BTEX dissolution rate in the presence of ethanol, preferable biodegradation of ethanol in gasohol plumes, which causes anoxic conditions for BTEX degradation, ${ }^{7,8}$ and gasohol contamination. ${ }^{9}$ Due to a cosolvent effect, ethanol reduces the interfacial tension of gasoline with respect to water content, which enables the gasoline-ethanol non-aqueous phase liquid (NAPL) to enter smaller pore spaces and to infiltrate more easily through the vadose zone towards the water table. ${ }^{10}$ Ethanol inhibits biodegradation of petroleum hydrocarbons, especially BTEX, by preferential degradation of the ethanol, causing preferential consumption of electron acceptors and nutrients, and changes to microbial populations that favor ethanol degraders. ${ }^{10}$ This negatively affects the ability of naturally occurring microorganisms to degrade harmful groundwater contaminants (natural attenuation). As a consequence, there is an increased proportion of dissolved plume of gasoline-contaminated groundwater, particularly benzene. $^{7}$

With the increased use of biofuels like ethanol, pure or mixed with fossil fuels, the effects of ethanol on the volatilization profiles of BTEX have become a matter of global concern, mainly the accidental soil spills. However, despite the well-known harmful effects of those chemicals, there is lack of quantitative analysis of the influence of ethanol on the evaporation rates of each individual component on gasoline-ethanol fuel. This is a particularly important issue because the evaporation profile of each BTEX compound may predict their transport and accumulation in soil and water sources. Therefore, the main objective of the present study was to perform a quantitative analysis of the influence of ethanol on the evaporation behavior and distribution of the individual BTEX compounds over the headspace, sand and water phases of experimental columns, simulating spills of neat gasoline and gasoline-ethanol.

\section{Experimental}

\section{Samples and solvents}

The samples of gasoline without ethanol were provided by Motors Laboratory of the Alberto Pasqualini Refinery, Brazilian Petroleum Agency (REFAP-Petrobrás). Anhydrous ethanol, BTEX standards and $n$-hexane were purchased from Merck (São Paulo, Brazil) and were used as received. All reagents and solvents used in this study were of analytical grade. The gasoline samples contain 30.63 (mass\%) of aromatics, 11.72 (mass\%) of alkanes, 17.90 (mass\%) of substituted alkanes and 39.75 (mass\%) of other components, and vapor pressure of $51.5 \mathrm{kPa} .{ }^{11}$

The Brazilian National Agency of Petroleum, Natural Gas and Biofuels (ANP) determines the characteristics of the fuel used in Brazil. The minimum ethanol content in AEAC is $99.3 \%$ by volume, and in AEHC $92.6 \%$ by volume. Gasoline $\mathrm{C}$ that results from the mixture of neat gasoline with $25 \%$ of ethanol must have a minimum motor octane number (MON) of $82 .{ }^{10}$ For Brazilian gasoline and gasoline-ethanol (24\% per volume in ethanol), the values for surface tension are 25.5 and $24.7 \mathrm{din}^{-1}$, respectively, and for interfacial tension the values are 16 and $10 \mathrm{din} \mathrm{cm}^{-1} \cdot{ }^{12}$

\section{Experimental columns}

In the present work, the sand phases (washed river sand, $110 \mathrm{~mm}$ high) of two glass columns were contaminated with neat gasoline and gasoline-ethanol. The sand was previously treated by Soxhlet extraction with $n$-hexane (4 h) and autoclave at $120{ }^{\circ} \mathrm{C}$ for $48 \mathrm{~h}$. The columns and the distilled water were also sterilized by autoclave $\left(120^{\circ} \mathrm{C}\right.$ for $15 \mathrm{~min}$ ) and had the following characteristics: height $0.3 \mathrm{~m}$, internal diameter $0.14 \mathrm{~m}$, total volume $4.62 \mathrm{~L}$. The columns were filled with distilled water $(100 \mathrm{~mL}$, $18 \mathrm{~mm}$ high), $5.0 \mathrm{~kg}$ sand (particle diameters ranging from 0.25 to $0.59 \mathrm{~mm}$, composed mostly of quartz, and uniformity coefficient and curvature coefficient of 1.08 and 0.89 , respectively) supported by a stainless steel divisor (1 mm mesh). The initial conditions of the columns were obtained by introducing $50 \mathrm{~mL}$ neat gasoline in the upper layer of column 1 (five contamination points, $10 \mathrm{~mL}$ at each point). The contamination points were made with a test tube to simulate a uniform fuel spill. Column 2 was contaminated in the same way with $50 \mathrm{~mL}$ of a 
gasoline-ethanol mixture (25\% v/v of ethanol). After the contamination, the junction between the column bodies and the caps were sealed with silicone to avoid vapor loss. Vapor leaks were checked twice daily (in morning and afternoon) with a water-ethanol mixture that was applied with a $1 \mathrm{~mL}$ syringe at different points of the junctions and the upper septum. No micro bubbles (indicating vapors leaks) were observed during the entire experimental period. The room temperature was monitored daily and showed an average value of $19.9 \pm 2.3^{\circ} \mathrm{C}$. Figure 1 shows a scheme of the experimental columns.

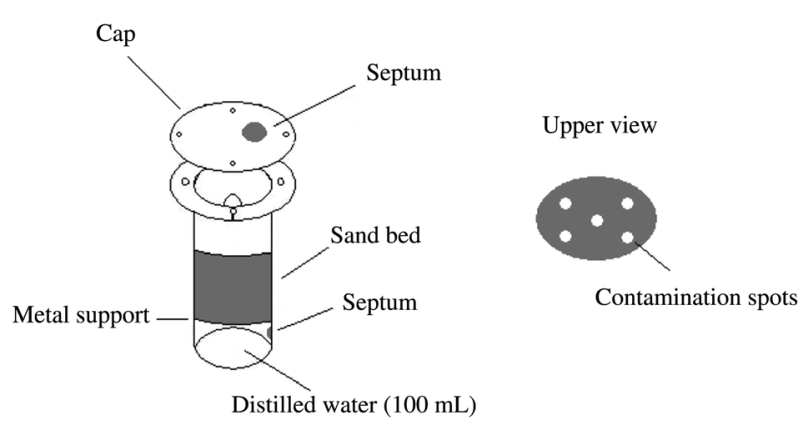

Figure 1. Scheme of the experimental columns.

The choice of sand as a soil model was based on the absence of the chemical organic groups, usually attached to the soil particles. These chemical groups may impair the study of BTEX volatilization based exclusively on the ethanol effect. In addition, sand appears to be a good model for the study of petroleum hydrocarbons in soil, plume behavior of petroleum hydrocarbons and naphthalene bioavailability. ${ }^{13-15}$

\section{Extraction procedures}

\section{Headspace}

The vapors in the experimental columns ( $150 \mathrm{~mm}$ high) were sampled by SPME (solid-phase microextraction) using an $85 \mu \mathrm{m}$ PDMS (polydimethylsiloxane) fiber (Supelco, Bellefonte, PA, USA) over 18 days. The first SPME sampling was performed $48 \mathrm{~h}$ after the columns closure by the septum perforation with the needle of the SPME holder. The fiber was exposed in the columns headspace for $15 \mathrm{~min}$. After this exposure time, the fiber was gathered and exposed again in the GC (gas chromatograph) injection port and maintained in this position during the entire run. The sampling interval was $30 \mathrm{~min}$.

Many works have been published regarding the equilibration time for the extraction of BTEX from aqueous or solid samples ranging from 5 to $20 \mathrm{~min} .{ }^{16-20}$ In the present work, no increase of the BTEX chromatographic peak areas were observed at extraction times longer than $15 \mathrm{~min}$. Therefore, in both columns, the fiber was exposed for $15 \mathrm{~min}$ and the SPME holder was adjusted to $4 \mathrm{~cm}$. The vapors were analyzed (in triplicate) via gas chromatography and the fiber was maintained for $15 \mathrm{~min}$ in the chromatograph injection port to avoid the carryover effect. After each sampling, $20 \mathrm{~mL}$ of the headspace vapors were flushed with a gas-tight syringe to force the system to reach a new equilibrium state by mass transfer of BTEX to the headspace. The interval between each sampling was $48 \mathrm{~h}$. Even though phase equilibrium should be within in few hours for NAPL such as BTEX, the interval of $48 \mathrm{~h}$ was necessary due to the GC availability for the instrumental analysis.

At the end of the experimental period, the sand and water phases were extracted as described below.

\section{Soil model (sand)}

Although labour-intensive, Soxhlet extraction is a well-established and widely used method for the extraction of solid samples including fuel contaminated soil. ${ }^{21-25}$

After the experimental period, the sand phase was placed in a plastic basin and homogeneously mixed with a small shovel. Aliquots of the sand phase $(10 \mathrm{~g}$ from each column) were extracted by Soxhlet in $125 \mathrm{~mL}$ of $n$-hexane for $4 \mathrm{~h}$. Afterwards, the organic extracts were reduced in volume (rotary evaporator) to $10 \mathrm{~mL}$ and then to $1.0 \mathrm{~mL}$ (fume hood). $1 \mu \mathrm{L}$ of the organic extracts was injected into the GC/FID (GC/flame ionization detector, triplicate of injection).

\section{Water}

The water samples were extracted using solid phase extraction (SPE) cartridges for the measurement of the concentrations of BTEX compounds added to the water phase. This method is well-established in the literature and was used for the determination of BTEX in river water. ${ }^{25}$ The $\mathrm{C}_{18}$ cartridges (Supelclean ${ }^{\mathrm{TM}}$, Supelco, $6 \mathrm{~mL}$ cartridges, $1.0 \mathrm{~g}$ sorbent mass) were previously conditioned on a SPE manifold at a flow rate of $1-2 \mathrm{~mL} \mathrm{~min}^{-1}$ with $15 \mathrm{~mL}$ of methanol followed by $15 \mathrm{~mL}$ of $n$-hexane. The cartridges were not allowed to run dry after conditioning. The samples were extracted under vacuum $\left(10 \mathrm{~mL} \mathrm{~min}^{-1}\right)$. The cartridges were dried under vacuum for $30 \mathrm{~min}$ prior to elution. BTEX were eluted from sorbents with $5 \mathrm{~mL}$ of $n$-hexane at a flow rate of $1 \mathrm{~mL} \mathrm{~min}^{-1}$. The organic extract volumes were reduced to $1.0 \mathrm{~mL}$ in a rotary evaporator. $1 \mu \mathrm{L}$ of the organic extracts was injected into the GC/FID (triplicate of injection).

The validation of the sampling and analysis methods were based on literature reports. ${ }^{16-26}$ 
Instrumental analysis

Instrumental analysis was performed with a gas chromatograph (PerkinElmer model Autosystem-XL) with flame ionization detection. A $30 \mathrm{~m}$ Elite column (film thickness $0.25 \mu \mathrm{m}$, internal diameter $0.25 \mathrm{~mm}$ ) was temperature programmed from $40{ }^{\circ} \mathrm{C}$ (held for $10 \mathrm{~min}$ ) to $220^{\circ} \mathrm{C}$ (held for $0 \mathrm{~min}$ ) at $5^{\circ} \mathrm{C} \mathrm{min}^{-1}$. The flow rate of the carrier gas (helium) was $1 \mathrm{~mL} \mathrm{~min}^{-1}$. The limit of detection for the pure BTEX was evaluated by instrumental analysis of BTEX solutions at 0.3, 0.5, 1.0, 2.5, 5.0, 10.0 and $20.0 \mathrm{mg} \mathrm{L}^{-1}$ obtained by successive dilutions of a BTEX standard solution in $n$-hexane $\left(100 \mathrm{~mL}, 50 \mathrm{mg} \mathrm{L}^{-1}\right)$.

\section{Results and Discussion}

In the present work, the LOD (limit of detection) was expressed as a concentration of the substance of interest that generates a detector signal twice the noise level (Table 1). ${ }^{27}$

Table 1. Parameters for the quality assurance of the quantification data used in the present study

\begin{tabular}{lccc}
\hline BTEX & $\begin{array}{c}\text { LOD / } \\
\left(\mathrm{mg} \mathrm{L}^{-1}\right)\end{array}$ & $\begin{array}{c}\text { Response } \\
\text { linearity / } \\
\left(\mathrm{mg} \mathrm{L}^{-1}\right)\end{array}$ & $\mathrm{R}^{2}$ \\
\hline $\begin{array}{l}\text { SPME extraction } \\
\quad \text { Benzene }\end{array}$ & 0.5 & $0.5-2.5$ & 0.9482 \\
$\quad$ Toluene & 0.5 & $0.5-2.5$ & 0.9811 \\
$\quad$ Xylenes & 5.0 & $5.0-20$ & 0.9750 \\
$\quad$ Ethylbenzene & 0.5 & $0.5-2.5$ & 0.9994 \\
\hline SPE and Soxhlet extractions & & & \\
$\quad$ Benzene & 2.5 & $2.5-20$ & 0.9955 \\
$\quad$ Toluene & 0.3 & $0.3-10$ & 0.9622 \\
$\quad$ Xylenes & 0.3 & $0.3-20$ & 0.9756 \\
$\quad$ Ethylbenzene & 0.5 & $0.5-10$ & 0.9833 \\
\hline
\end{tabular}

LOD: limite of detection; $\mathrm{R}^{2}$ : correlation coefficient.

\section{Concentration in the headspace}

Figure 2 shows the average concentrations $(n=3)$ of BTEX at each sampling in the headspace of the neat gasoline and gasoline-ethanol columns.

As can be seen in Figure 2, all BTEX compounds show slight improvement on concentration levels in the headspace of the gasoline-ethanol column. However, these improvement are apparently non-linear up to the fourth sampling. Strong fluctuations in concentrations were observed, mainly in the headspace of the neat gasoline column. In order to obtain a clearer picture of the volatilization behavior of each BTEX compound, another approach, considering only the final and initial concentrations, was adopted. This is an interesting approach because the relative variations in BTEX concentrations are independent of the compound proportions in both columns. Furthermore, this approach may compensate for the impossibility of mass balance calculations since BTEX concentrations in gasoline are unknown.

Figure 3 shows the relative volatilization of BTEX in the headspace of the experimental columns, considering the final and initial states of the entire experimental period.

The relative volatilizations of benzene, toluene, xylenes and ethylbenzene in the neat gasoline column were $86.51,1.20,75.51$ and $81.21 \%$, respectively. The same trend was observed in the gasoline-ethanol column. However, generally speaking, the relative volatilizations were larger in the ethanol-gasoline column $(88.21,74.92,80.53$ and $80.36 \%$, for benzene, toluene, xylenes and ethylbenzene, respectively). It is assuming that after each sampling the most volatile compounds showed a new concentration similar to the original ones. Consequently, the minor variation of the concentration between the final and initial states would be related to volatilization. According to this approach, toluene and ethylbenzene showed the highest volatilizations and these results can be better explained by the strong permanent dipole interactions ${ }^{28}$ among ethanol, toluene and ethylbenzene molecules.

Intermolecular forces play an important role in the chemistry of polar compounds. Kanai et al..$^{29}$ used the theory of intermolecular forces to explain the chromatographic separation of meta and para isomers of xylenes. Cataluña and Silva ${ }^{30}$ described the development of a device to determine the vapor pressure and the vaporization enthalpy of formulations containing volumes of 5, 15 and $25 \%$ of ethanol in four base gasolines. The referred authors found that the addition of ethanol to gasoline hydrocarbons generates a mixture with a boiling point lower than that of the original compounds. Thus, interfacial tension is directly related to vapor pressure and is mandatory in mass transfer phenomena. According to McDowell and Powers, ${ }^{31}$ ethanol affects BTEX volatilization by altering the proportions of compounds in the mixture and by changes in the interfacial and surface tension (cosolvent effect).

The highest relative volatilization of toluene and ethylbenzene in the gasoline-ethanol column could be due to the lowering of the mixture boiling point with the consequent volatilization increase (dipole interactions plus colsolvent effect). Since the average dipole moment $(\mu)$ of xylenes is lower than that of toluene and ethylbenzene (Table 2), their interaction with ethanol molecules, and consequently their volatilization, is less intense. 

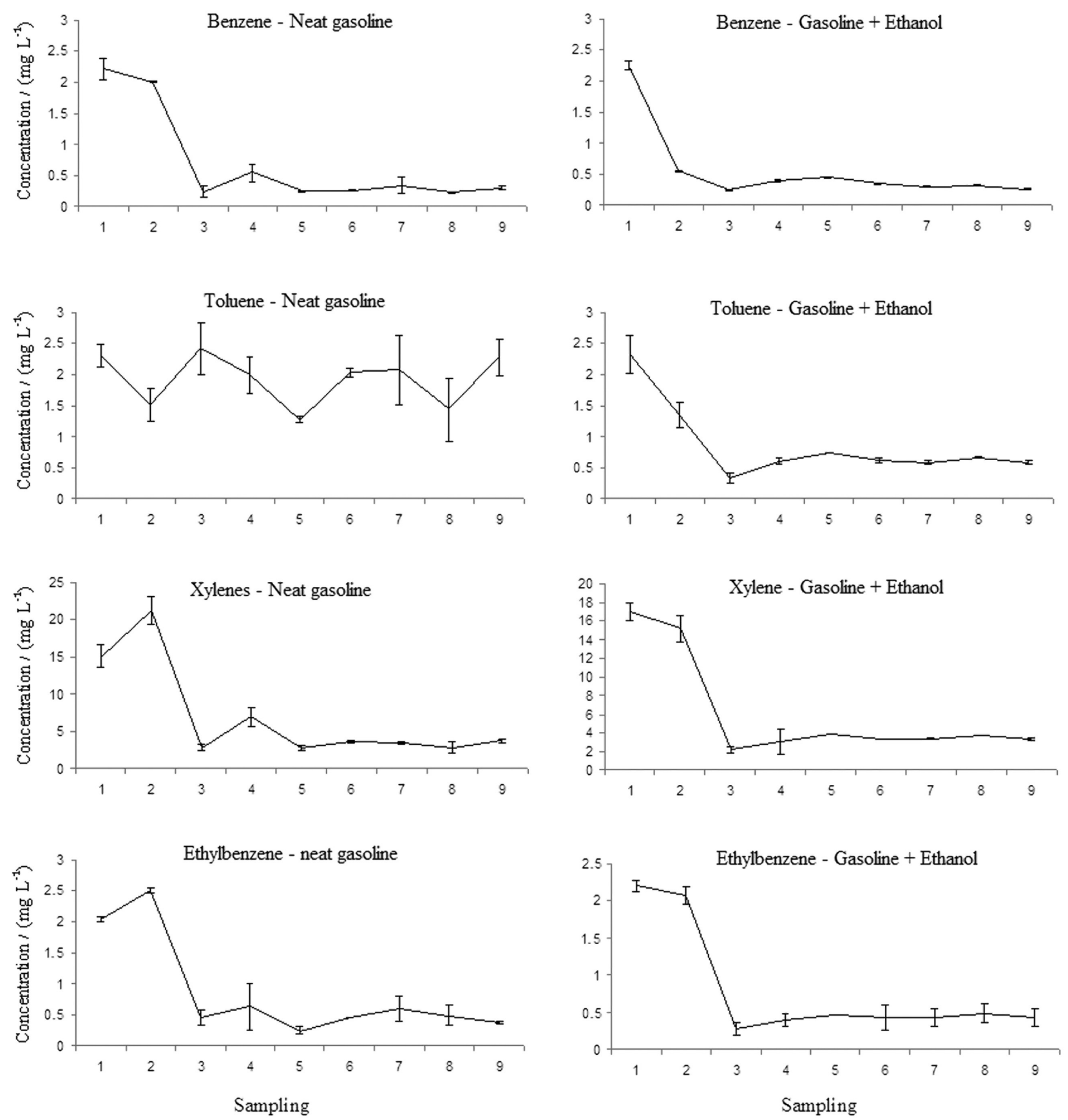

Figure 2. Average concentrations of BTEX at each sampling period in the headspace of the neat gasoline and gasoline-ethanol columns. Error bars represent standard deviations.

However, the high volatilization profile of benzene in the headspace of both columns cannot be explained by dipole interaction since the dipole moment of benzene is zero. Consequently, these results must be explained by the highest vapor pressure of benzene (Table 2).

\section{Distribution in the column compartments}

Figure 4 shows the relative distributions of BTEX in the experimental columns, considering the sum of the concentrations in the three compartments at the end of the experimental period.

Regarding the distribution in the sand phase, no significant differences were observed between the neat gasoline and the gasoline-ethanol columns.

The decrease of the BTEX concentrations in the aqueous phase of the gasoline-ethanol column was as follows: -4.05 , -6.99 and $-10.62 \%$ for benzene, xylene and ethylbenzene, respectively. The biggest reduction in the ethylbenzene concentration in this compartment can be explained by the 

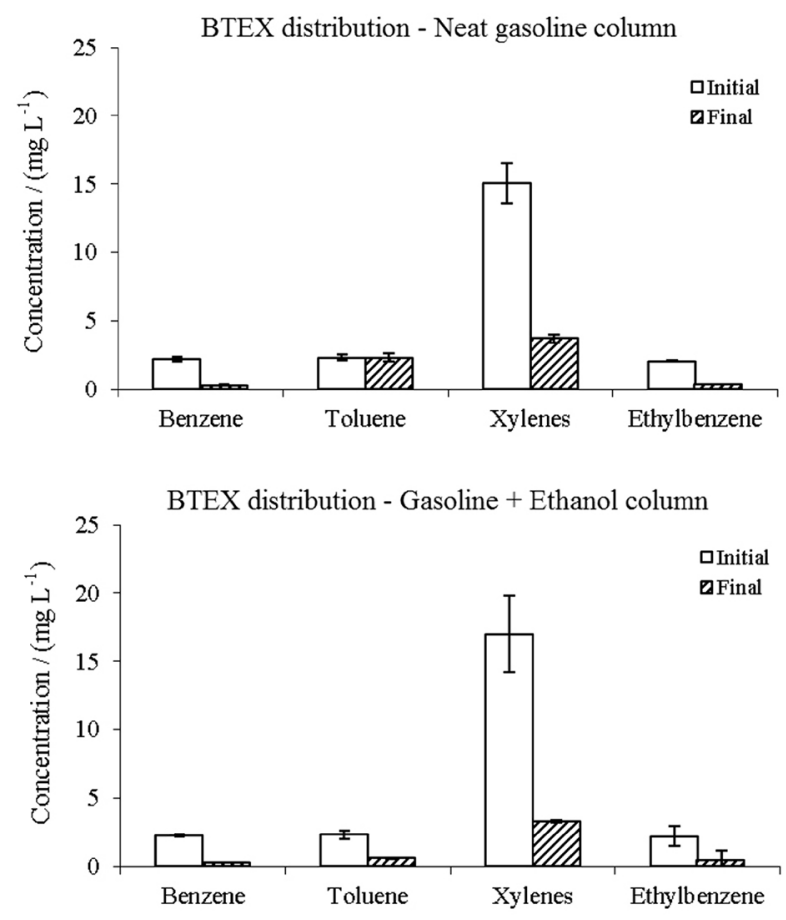

Figure 3. Volatilization of BTEX in the headspace of the neat gasoline and gasoline-ethanol columns, considering the final and initial times of the entire experimental period. Error bars represent standard deviations.

Table 2. Dipole moments and vapor pressures of ethanol and BTEX ${ }^{32-34}$

\begin{tabular}{lccc}
\hline Compound & $\begin{array}{c}\mu^{\mathrm{a}} / \\
\mathrm{D}\end{array}$ & $\begin{array}{c}\text { Vapor pressure / } \\
\mathrm{atm}\end{array}$ & $\begin{array}{c}\text { Water solubility / } \\
\left(\mathrm{mg} \mathrm{L}^{-1}\right)\end{array}$ \\
\hline Ethanol & 1.69 & 0.058 & $\infty$ \\
Benzene & 0 & 0.12 & 175 \\
Toluene & 0.37 & 0.037 & 0.037 \\
Xylenes & $0.30^{\mathrm{b}}$ & $0.0036^{\mathrm{b}}$ & $0.0036^{\mathrm{b}}$ \\
Ethylbenzene & 0.64 & 0.009 & 0.009 \\
\hline
\end{tabular}

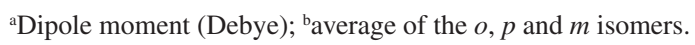

greater distribution in the headspace as discussed above. However, the differences in the results of xylene and toluene concentrations ( -6.99 and $-4.89 \%$, respectively) were unexpected and cannot be explained only by dipole interactions or cosolvency approach. The determination of BTEX in environmental matrices is difficult because of the losses incurred during sample handling and extraction. Mottaleb et al. ${ }^{25}$ for example, reported a method that uses solid-phase extraction $\left(\mathrm{C}_{18}\right)$ with dichloromethane as eluent for the determination of BTEXC (BTEX plus cumene) in river water. According to the authors, higher recoveries were obtained for xylenes and cumene, and this may be due to a more non-polar interaction between the bonded phase and the $\mathrm{CH}_{2} \mathrm{Cl}_{2}$ system. However, the eluent used in the present work was $n$-hexane (less polar than dichloromethane), which was probably not efficient enough
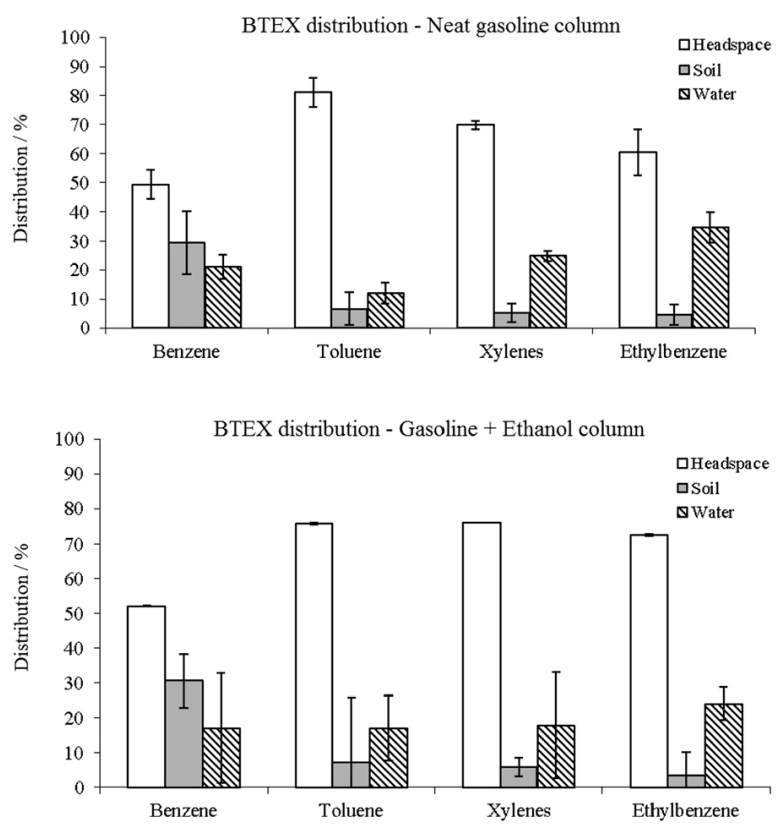

Figure 4. Distribution of BTEX in the compartments of neat gasoline and gasoline-ethanol columns. Error bars represent standard deviations.

to desorb the xylenes from the $\mathrm{C}_{18}$ solid phase. This may explain the larger reduction of xylene concentration in the water phase of the gasoline-ethanol column.

Pasteris et al..$^{35}$ reported similar gas phase distributions of toluene and $m$-xylene and assessed the vapor phase transport and biodegradation of gasoline compounds. However, no comparisons were made using gasolineethanol fuel. Dakhel et al. ${ }^{36}$ reported the fate of methyl tert-butyl ether (MTBE), ethanol, benzene and other selected petroleum hydrocarbons in a controlled gasoline spill experiment. However, the volatilizations of ethylbenzene, toluene and xylenes were not evaluated in that study. In a previous work from our research group, ${ }^{37}$ the volatilizations of benzene, toluene and xylenes were measured in larger Plexiglass columns without the water phase. The concentration of benzene in the vapor phase of the gasoline-ethanol column was decreased. On the other hand, concentrations of toluene and xylenes in the vapor phase of the gasoline-ethanol column increased drastically. The volatilization of ethylbenzene was not evaluated in those studies.

The solubility of BTEX in water may appear unachievable due to the large differences in polarity. However, Feller ${ }^{38}$ reported that the purely electronic binding energy, in the complete basis set limit, was $-3.9 \pm 0.2 \mathrm{kcal} \mathrm{mol}^{-1}$, or only $20 \%$ weaker than the water-water interaction. According Mazzeo et al. ${ }^{39}$ the high solubility of BTEX in water represents a serious risk of groundwater contamination. Thomas et al..$^{40}$ and Hosseinzadeh et al. ${ }^{41}$ also reported the solubility of BTEX in water. 
To the best of our knowledge, the present work is the first one reporting measurements of the volatilization of BTEX compounds in the three compartments of laboratory sand columns and discussing the role of intermolecular dipole forces on the volatilization profiles of BTEX. Thus, despite the substantial body of published work that has examined the impact of ethanol on BTEX vapor pressure and partitioning into the aqueous phase, our data is not comparable to other published research.

\section{Conclusions}

Ethanol is likely to increase BTEX distribution in the headspace. Thus, the addition of ethanol to gasoline may have negative effects on the atmospheric environment. Based on the results of the present study, it can be inferred that, in the case of gasoline-ethanol soil spills, toluene and ethylbenzene will be rapidly emitted into the air. The largest increase in benzene concentration in the soil phase of the gasoline-ethanol column suggests that this compound may be the main contaminant remaining on this compartment, in the case of gasoline-ethanol spills in soil.

Our group will undertake a further assessment of BTEX distribution using standard mixtures in the same experimental columns. Consequently, the matrix interference and the exact concentrations of each compound will be determined in the three compartments. The group also intends to use other solvents or solvent mixtures to improve desorption of xylenes from the $\mathrm{C}_{18}$ solid phase.

\section{Acknowledgements}

The authors thank Conselho Nacional de Desenvolvimento Científico e Tecnológico (CNPQ), Pronex, Fundação de Amparo à Pesquisa do Estado do Rio Grande do Sul (Fapergs)/CNPq, and the University of Caxias do Sul for financial support and the Alberto Pasqualini Refinery-Brazilian Petroleum Agency (REFAPPetrobrás) for supplying the gasoline samples.

\section{References}

1. Lei Federal Brasileira No. 8723 de 28 de outubro de 1993, Dispõe sobre A Redução de Emissão de Poluentes por Veículos Automotores e dá outras Providências, 1993, http://www. planalto.gov.br/ccivil_03/leis/L8723.htm accessed in October 2012.

2. http://www.desenvolvimento.gov.br/sitio/interna/interna. php?area=2\&menu=3652, accessed in March 2013.

3. Nerantzis, P. C.; Dyer, M. R.; Geotech. Geol. Eng. 2010, $1,1$.
4. DeHate, R. B.; Johnson, G. T.; Harbison, R. D.; Regul. Toxicol. Pharm. 2011, 59, 353.

5. Dawson, J. J. C.; Iroegbu, C. O.; Maciel, H.; Paton, G. I.; J. Appl. Microbiol. 2008, 51, 141.

6. Shin, D.; Moon, H. S.; Lin, C. C.; Barkay, T.; Nam, K.; Environ. Pollut. 2011, 14, 509.

7. Da Silva, M. L. B.; Alvarez, P. J. J.; J. Environ. Eng. 2002, 128, 862.

8. Yu, S.; Freitas, J. G.; Barker, J. F.; Chatzis, J.; J. Contam. Hydrol. 2009, 105, 1.

9. Silva, M. L. B.; Courseuil, H. X.; Int. Biodeterior. Biodegrad. 2012, 67, 21.

10. Niven, R. K.; Renewable Sustainable Energy Rev. 2005, 9 , 535.

11. Agência Nacional do Petróleo, Gás Natural e Biocombustíveis (ANP), Portaria ANP No. 126, DOU 9.8.2002, 2002.

12. Finotti, A.; Caicedo. N.; Oliveira, E.; Zoby, J. L.; Int. Assoc. Hydrol. Sci. 2005, 297, 197.

13. Baek, S. S.; Kim, S. B.; Kim, D. J.; Hydrol. Process. 2003, 17, 1239.

14. Ojuri, O. O.; Ola, S. A.; Mar. Georesour. Geotechnol. 2010 , $28,154$.

15. Burgos, W. D.; Berry, D. F.; Bhandari, A.; Novak J. T.; Water Res. 1999, 33, 3789.

16. Djozan, D.; Assadi, Y.; Haddadi, S. H.; Anal. Chem. 2001, 73, 4054.

17. Prikryl, P.; Kubinec, R.; Jurdakova, H.; Sevcık, J.; Ostrovsky, I.; Sojak, L.; Berezkin, V.; Chromatographia 2006, 64, 65.

18. Lee, M.; Chang, C.; Dou, J.; Chemosphere 2007, 69, 1381.

19. Telgheder, U.; Malinowski, M.; Jochmann; M. A.; Int. J. Ion Mobility Spectrom. 2009, 12, 23.

20. Su, F.; Lu, C.; Hu, S.; Colloid Surf., A 2010, 353, 83.

21. Hung, J.; Liu, H.; Hwu, C.; Tsao, C.; Lai, H.; Lu, C.; J. Environ. Biol. 2011, 32, 277.

22. Łebkowska, M.; Zborowska, E.; Karwowska, E.; Miáskiewicz-Peska, E.; Muszynski, A.; Tabernacka, A.; Naumczyk, J.; Jeczalik, M.; Ecol. Eng. 2011, 37, 1895.

23. Plaza, G.; Nalecz-Jawecki, G.; Ulfig, K.; Brigmon, R. L.; Chemosphere 2005, 59, 289.

24. Singh, C.; Lin, J.; Afr. J. Biotechnol. 2009, 8, 3286.

25. Smith, M. J.; Flowers, T. H.; Duncan, H. J.; Saito, H.; J. Hazard. Mater. 2011, 192, 1219.

26. Mottaleb, M. A.; Abedin, M. Z.; Islam, M. S.; Anal. Sci. 2003, 19, 1365.

27. Campos-Candel, A.; Llobat-Esttellés, M.; Mauri-Aucejo, A.; Talanta 2009, 78, 1286.

28. Qiu, H.; Takafuji, M.; Liu, X.; Jiang, S.; Ihara, H.; J. Chromatogr., A 2010, 1217, 5190.

29. Kanai, H.; Inouye, V.; Yazawa, L.; Goo, R.; Wakatsuki, H.; J. Chromatogr. Sci. 2005, 43, 57.

30. Cataluña, R.; Silva, R.; Quim. Nova 2006, 29, 580. 
31. McDowell, C. J.; Powers, S. E.; Environ. Sci. Technol. 2003, $37,1803$.

32. Qu, F.; Zhu, L.; Yang, K.; J. Hazard. Mater. 2009, 170, 7.

33. Howard, P. H.; Handbook of Environmental Fate and Exposure Data for Organic Chemicals; Lewis: Boca Raton, Florida, USA, 1990.

34. Lide, D. R.; Handbook of Chemistry and Physics; CRC Press: Boca Raton, Florida, USA, 1996.

35. Pasteris G.; Werner, D.; Kaufmann, K.; Höhener, P.; Environ. Sci. Technol. 2002, 36, 30.

36. Dakhel, N.; Pasteris, G.; Werner, D.; Höhner, P.; Environ. Sci. Technol. 2003, 37, 2127
37. Cagliari, J.; Fedrizzi, F.; Finotti, A. R.; Teixeira, C. E.; Nascimento, I. F.; Environ. Toxicol. Chem. 2010, 29, 808.

38. Feller, D.; J. Phys. Chem. A 1999, 103, 7558.

39. Mazzeo, D. E. C.; Levy, C. E.; Angelis, D. F.; Marin-Morales, M. A.; Sci. Total Environ. 2010, 408, 4334.

40. Thomas, S. P.; Ranjan, R. S.; Webster, G. R. B.; Sarna, L. P.; Environ. Sci. Technol. 1996, 30, 1521.

41. Hosseinzadeh, R.; Tahmasebi, R.; Farhadi, K.; MoosaviMovahedi, A.A.; Jouyban, A., Badraghi, J.; Colloid Surface B 2011, 84, 13. 